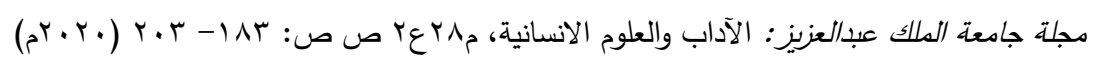

DOI:10.4197/Art.28-2.7

\title{
المساندة الإجتماعية وفعالية الذات وعلاقتهما بجودة الحياة لدى عينة من طالبات الجامعة بمحافظة جدة
}

\author{
د. شروق غرم الله الزهراني \\ أستاذ مساعد- قسم علم النفس - كلية العلوم الإجتماعية - جامعة جدة
}

مستخلص. هدفت الدراسة الحالية إلى التعرف على العلاقة بين المساندة الإجتماعية وجودة الحياة ، وكذلك

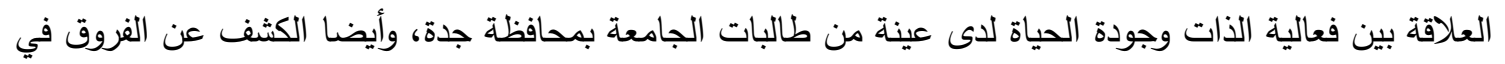

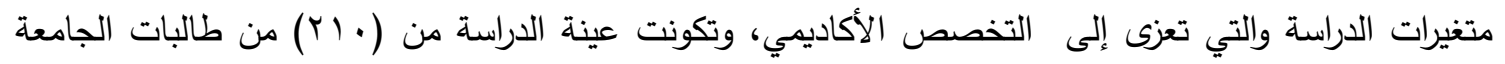
تراوحت أعمارهن بين (YV،Y (YV) سنة، وطبقت مقاييس المساندة الإجتماعية، وفعالية الذات ، وجودة الحياة، وأسفر

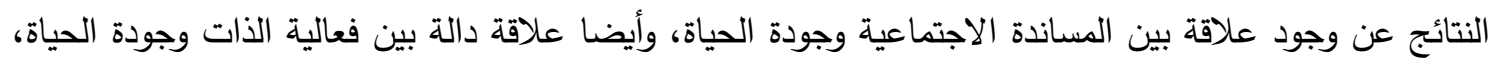
كما ظهر عدم وجود فروق في كل من المساندة الاجتماعية، وفعالية الذات، وجودة الحياة تعزى إلى التخصص وجص ونه الاكاديمي. كلمات دالة: المساندة الاجتماعية- فعالية الذات- جودة الحياة- طالبات الجامعة.

الحياة والرضا عنها وهو أمر مطلوب في ظل

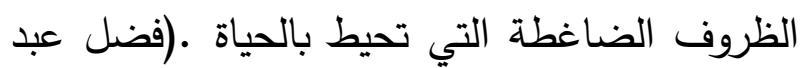

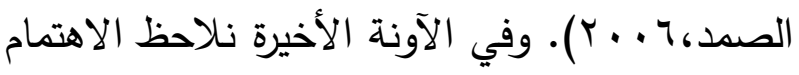
بمفهوم الجودة بشكل عام وجودة الحياة بشكل خاص، وهذا الاهتمام يعكس أهمية هذا المفهوم وتأثيره على مختلف الجوانب النفسية، وتعد جودة الحياة تعبير عن الإدراك الذاتي لتلك الجودة، فالحياة

\section{المقدمة}

إن علم النفس الإيجابي لله دور في فحص الجوانب

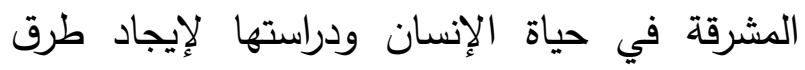

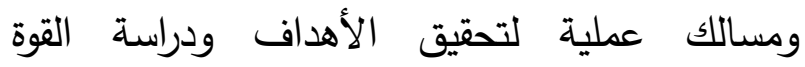

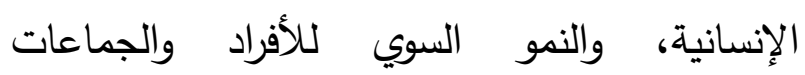

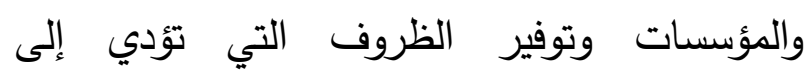
مستويات عالية من السعادة والأمل والتفاؤل وحب وتؤي 
تستلزم وجود اشخاص يتسمون بالمساندة والدعم

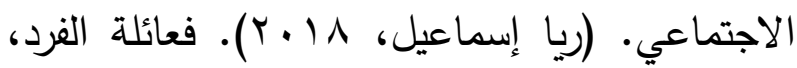
وأصدقائه، و جيرانه يشكلون مصادر دعم اجتماعي إنماعل، له، و مكن تصنيف الدعم الاجتماعي إلى ثلاث مجموعات: المالية والعاطفية والمعرفية. الدعم المالي لهي ينطوي على توفير المال والغذاء. والدعم العاطفي ولهي

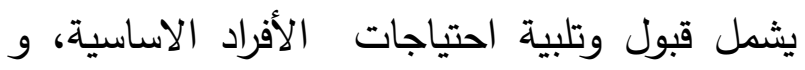
الاجتماعية مثل الحب والانتباه والثقة، والثعور بالانتماء إلى مجموعة الدعم المعرفي يشير إلى مئى توفير المعلومات ومساعدة الأفراد في حل مشاكلهم.

( Backstrom\&others,2017) وتعد فاعلية الذات من المتغيرات النفسية الهامة التي توجه سلوك الفرد وتسهم في تحقيق أهدافه الشخصية، والمعتقدات التي يمتلكها الفرد حول قدراته وإمكاناته لها دور هام في التحكم في البيئة؛ مما يسهم في زيادة قدرة الفرد على الإنجاز ونجاح

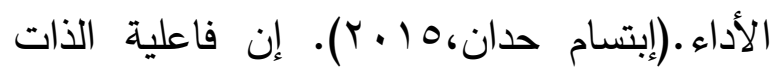
إحدى موجهات السلوك، فالفرد الذي يؤمن بقدرته يكون أكثر نشاطاً وتقديراً لذاته، ويمثل ذلك مرآة

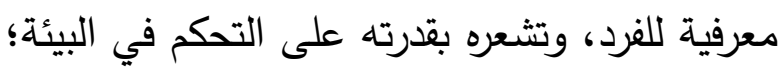
حيث تعكس معتقدات الفرد عن ذاته قدرته على ولى بعديه التحكم في معطيات البيئة من خلال الأفعال والوسائل التكيفية التي يقوم بها، والثقة بالنفس في مواجهة ضغوط الحياة.(ليلى المزروع، . . . Y).
بالنسبة للفرد ما يدركه منها، فشعور الفرد بالرضا عن حياته ينعكس على عمله ويتجلى ذلك في معدل

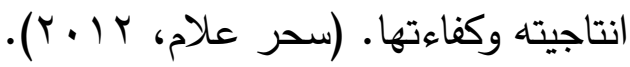
والشعور بجودة الحياة يزداد أو يقل وفق المنظومة المحيطة بالفرد التي تمتد لتشمل المساندة الاجتماعية التي تقدم للأفراد لمواجهة ضغوط الحياة، كما أنها

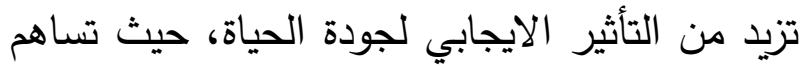
المساندة الاجتماعية المادية والمعنوية برؤية تنبؤيه للحياة تساعد لمواجهة أضرارها، وتقلل من الضغوط

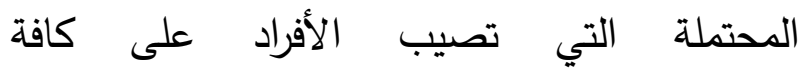

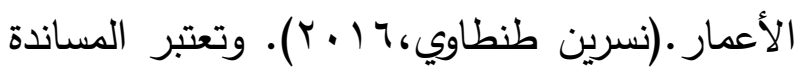

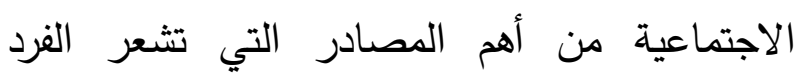
بالتقدير والاعتراف والقبول. كما تعتبر مصدر هام من مصادر التخفيف من ضغط العمل لاى الأفراد، إذ تساعدهم على التكيف مع المشكلات التي

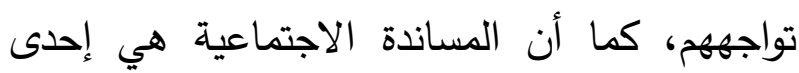

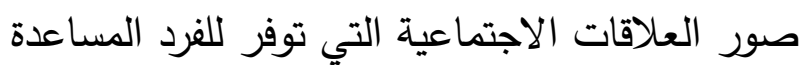

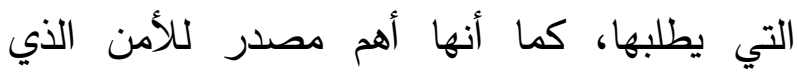

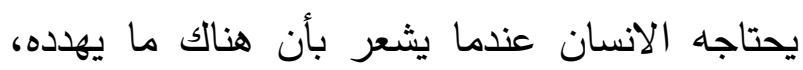

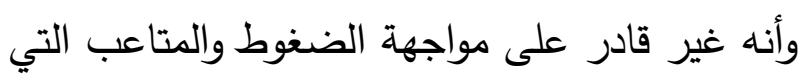

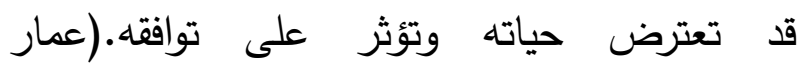

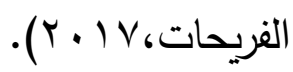
إن المساندة الاجتماعية بجميع اشكالها تؤدي الى لى اشباع الحاجات الأساسية للفرد من حب واحترام وتقهم وتواصل وتقديم المعلومات من الأشخاص ذوي الأهمية في حياة الفرد وبهذا فالمساندة الاجتماعية 
كما تعتبر فعالية الذات من الجوانب المكونة لشخصية الإنسان، ففكرة الفرد عن نفساه، وإيمانه

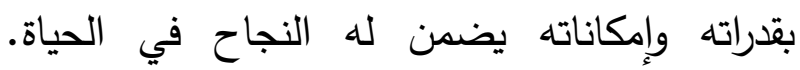
فمعتقدات الفرد عن فاعليته الذاتية تعكس قدرته على أن يتحكم في معطيات البيئة من خلال أفعاله، ووسائل التكيف التي يستخدمها، والثقة بالنفس في مواجهة الضغوط والاضطرابات النفسية والجسدية الناجمة عن الصعوبات الحياتية.(إبتسام

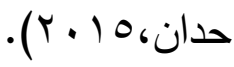

وتمثل فعالية الذات أحد الأبعاد المهمة في تحسين جودة الحياة، وانطلاقا من نتائج البحوث والدراسات

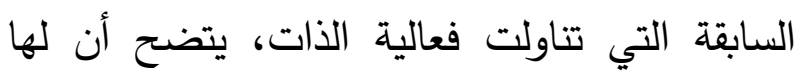

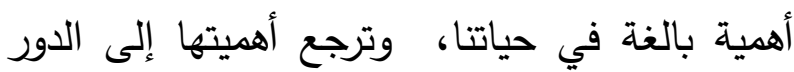
الحيوي الذي تؤديه في دفع السلوك وتوجيهه نحو تحقيق الأهداف التي تسعى إلى تحقيقها ، كما تعمل

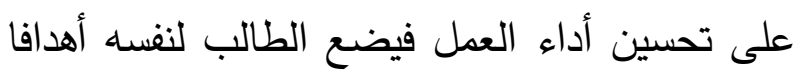
بعيدة المدى، ويبذل الجهد في مواجهة الفشل، وينظر للمهام الصعبة على أنها مصادر للتحدي. وفي ولي ضوء ما سبق تظهر الحاجة لإجراء مثل هذه الدراسة للتعرف على مدى تأثير كل من المساندة الاجتماعية وفعالية الذات في تحقيق جودة الحياة لدى طالبات الجامعة • ويمكن صياغة مشكلة الدراسة في

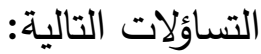

1- هل توجد علاقة بين المساندة الاجتماعية

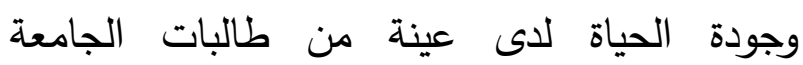

مثكلة الدراسة وتساؤلاتها: يشكل طلبة الجامعة شريحة هامة من شرائح

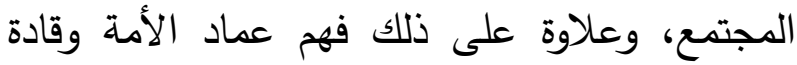
الغد، ولقد أصبح الاهتمام بفئة الطلاب الجامعيين ودراسة خصائصهم ومعرفة حاجياتهر من أبرز الاهتمامات لدى المجتمعات كافة ويأتي ذلك دئك الاهتمام بهذه الفئة من منطلق أهميتها فهم يشكلون ثروة قومية ورأس مال ثمين يساعد على النمو والتقدم

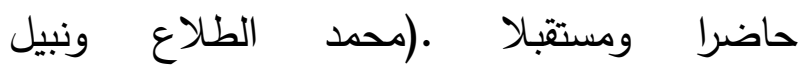

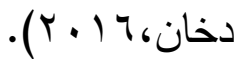
وتعد جودة الحياة من المتغيرات المؤثرة في حياة الطلاب، والتي تشكل قيمة للحياة في الحاضر والمستقبل، ويسعون إلى تحقيق مزيد من السعادة

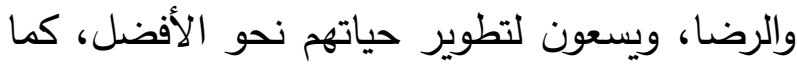
أن تحسين جودة الحياة من المؤشرات الهامة الدالة على تقدم المجتمع، وتتعكس على رضا الفرد واحساسه بالسعادة.

وتعد المساندة الاجتماعية من المطالب الأساسية لجميع افراد المجتمع للحصول على الدعم والرعاية والاهتمام من قبل المحيطين بهم لزيادة الشعور بالرضا وتقدير الذات والثقة ومقاومة احداث الحياة السلبية وتجاوز الأزمات، فبدون المساندة الاجتماعية يصبح الفرد معرضا لكثير من المخاطر والاضرار البيئية التي تؤدي الى عزلته عن الآخرين.(ريا

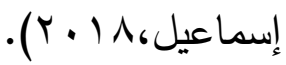


r- توفير إطار نظري للمساهمة في الكشف عن

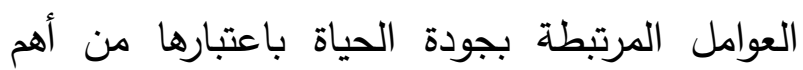
المتغيرات المؤثرة في حياة طلاب الجامعة. r- ستسهم نتائج الدراسة في المساعدة في تفعيل

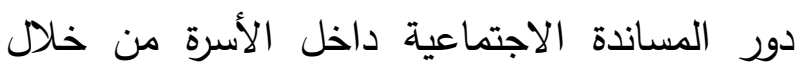
تعرفهم على مدى انعكاس اثر المساندة على جودة الحياة لاى الطلاب. ع- تفتح الدراسة الحالية المجال للباحثين والمهتمين لإجراء دراسات أخرى على نفس العينة من خلال النتائج والتوصيات والمقترحات المطروحة.

\section{الأهمية التطبيقية:}

1- ستسهم الدراسة الحالية في مساعدة المهتمين

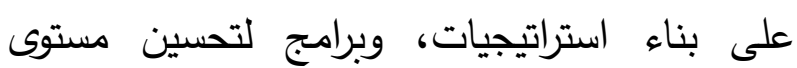
الفاعلية الذاتية، وتتميتها لدى فئة الدراسة. r- ستسهم نتائج الدراسة في مساعدة المهتمين في

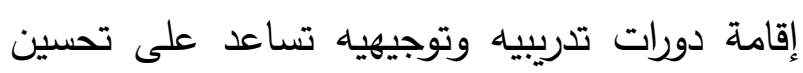
جودة الحياة لدى الثباب. r- ستسهم نتائج الدراسة الحالية في تصميم برامج إرشادية تفيد في رفع مستوى التماسك الأسري.

\section{متغيرات الاراسة:}

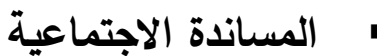

- تعرف أسماء السريسي وأماني عبد المقصود

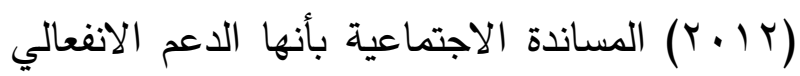
والمادي والأدائي الذي يتلقاه الفرد من قبل الآخرين المحيطين به والأسرة والأصدقاء والجيران وزملاء

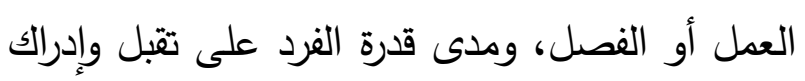

r- هل توجد علاقة بين فعالية الذات وجودة الحياة لاى عينة من طالبات الجامعة بمحافظة جدة؟ بوج عاله r- هل توجد فروق في متوسطات درجات الطالبات في كلا من المساندة الإجتماعية وفعالية الذات وجودة الحياة والتي تعزى إلى التخصص الأكاديمي؟ أهداف الاراسة:

تهدف الدراسة الحالية إلى: 1- الكثف عن العلاقة بين المساندة الاجتماعية وجودة الحياة لاى عينة من طالبات الجامعة

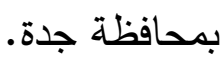
r- الكثف عن العلاقة بين فعالية الذات وجودة الحياة لدى عينة من طالبات الجامعة بمحافظة جدة. r- التحقق من الفروق في كلا من المساندة الإجتماعية وفعالية الذات وجودة الحياة لاىى عينة من طالبات الجامعة بمحافظة جدة وفقا للتخصص وفصل لإنه

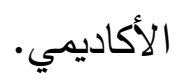

\section{أهمية الدراسة}

الأهمية النظرية:1- تكتسب الدراسة أهميتها من أهمية العينة التي تتناولها وهي طالبات الجامعة حيث تعتبر مرحلة النهوض بأنفسه ومجتمعاتهم إلى أعلى درجات

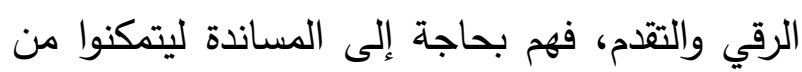
تحقيق ذواتهم وتنمية شخصياتهم وتحقيق التقدم ل لمجتمعاتهم. 
اعتقاد الفرد عن قدراته في أداء أفعال أو مهام محددة.)(Erozkan , 2014). -وتعرفها الباحثة بأنها معتقدات الفرد حول قدراته التي تؤثر على أدائه للمهام المختلفة، وتقاس بالدرجة التي يحصل عليها المفحوص على مقياس فعالية الذات المستخدم في الدراسة الحالية. وتتضمن فعالية الذات الأبعاد التالية إنجاز الأداء:- قناعة الفرد بقدرته الذاتية على أداء المهام الصعبة، وانجازها بنجاح ، مما يقتضي تتظيم تفكيره، وتقييمه لأدائه، ومواجهة الصعاب وتحمله المسؤولية، والمثابرة في تحقيق أهدافه مع شعوره بالثقة بنفسة. الخبرات البديلة:- كل ما يمكن اكتسابه من خلال ملاحظات الآخرين ، وأنشطتهم الناجحة ، وكذلك ما يمر باه من خبرات سابقة، مما يساعد الفرد على تكوين توقعات عن أدائه في المواقف المشابهة. الاقتناع:- قدرة الفرد ومهارته للاستمتاع إلى الآخرين أثثاء تقديم عمليات التشجيع والتدعيم، والتي تهدف إلى إقناعه بقدرته على إنجاز المهام بنجاح. (هويدا محمود و فوزية الجمالي، • ( • ب).

\section{جودة الحياة}

يعد مفهوم جودة الحياة من المفاهيم الواسعة متعددة الأبعاد، والذي يهدف الى تقييم حياة الشخص وفقاً للمعايير العالمية، كما يختلف تعريف جودة الحياة نتيجة لاختلاف توجهات الباحثين ورؤيتهم حول جودة الحياة، وما يرتبط بها من متغيرات اجتماعية
هذا الدعم. وهي جميع الأشكال من العلاقات الثخصية الطوعية الموجهة نحو توفير المساعدات المالية والعاطفية ، والمعرفية. ) ( Mermer, Bilge, (Yucel, Ceber,2010 وتعتبر المساندة الاجتماعية مصدرا هاما من مصادر الدعم النفسي والاجتماعي الذي يحتاجه الفرد في حياته اليومية، كما أنها تلعب دورا هاما في اشباع حاجاته للأمن النفسي والاجتماعي في عالمه الذي يعيش فيه عندما يشعر أن هنالك ما يهدده، وأن طاقته استنفذت، وأنه يحتاج إلى مدد وعون خارجي.(أسماء البليطي، V I . Y). وتعرف الباحثة المساندة الاجتماعية إجرائيا بأنها: مختلف أشكال الدعم المادي والمعنوي الذي يتلقاه الفرد ممن يحيطون به سواء أفراد أسرته أو أصدقائه أو جيرانه، وتقاس دن خلال الدرجة التي تحصل عليها الطالبة على مقياس المساندة الاجتماعية المستخدم في الدراسة الحالية. فعالية الذات التهات

يعرف باندورا Bandura فعالية الذات بأنها حالة دافعية يتم من خلالها قياس التقدير الذاتي للفرد على تتفيذ أعمال معينة لتحقيق بعض أهدافه، واعتقاداته حول ما يمكنه القيام به..( Bandura,2007) وهي معتقدات يمتلكها الفرد تحدد قدرته على أداء السلوك وتوجيهاه، مما ينعكس على الأنشطة التي يقوم بها، والكيفية التي يتعامل معها في المواقف التي تواجها

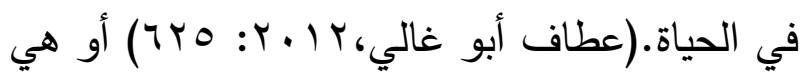


- مجال الصحة الجسمية: وهو إدراك الفرد لجودة حياته من ناحية النشاط أو الطاقة، والتعب، والألم، وعدم الراحة، والنوم، والراحة.

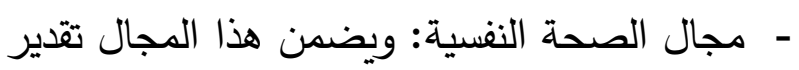
الفرد لجودة حياته من عدة جوانب أههها: المظهر ، وصورة الجسم، والمشاعر السلبية والايجابية، وتقدير الذات، والتنكير والتعلم والذاكرة والتركيز والانتباه.

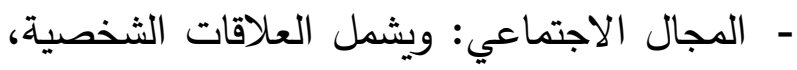
والدعم الاجتماعي الذي يتلقاه الفرد.

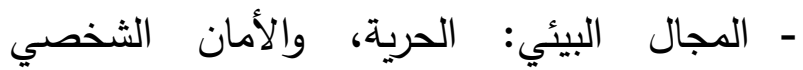
والجسمي، والرعاية الصحية، وبيئة المنزل، والأنشطة الترفيهية، والتلوث، والضوضاء. كما أوضح Ventegrative, et al(2003 أن جودة، واءة الحياة تتضمن بعدين جودة الحياة الذاتية وتشمل أبعاد فرعية تتمثل في (طيب الحياة، والرضا عن بطدئ الحياة، والسعادة، ومعنى الحياة)، وجودة الحياة الموضوعية وتشمل أبعاد فرعية تتمثل في (المعايير الثقافية، واشباع الحاجات، وإدراك الأككانيات

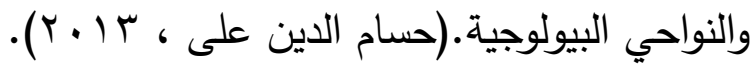

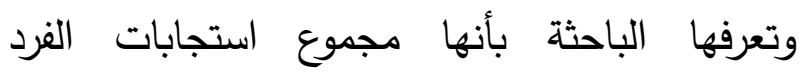
الإيجابية نحو الحياة، وإحساسه بأهميتها وقيمتها ورضاه عن حياته بشكل عام. وتقاس من خلال الدرجة التي يحصل عليها المفحوص على مقياس جودة الحياة المستخدم في الدراسة الحالية.
او نفية، أو صحية، أو اقتصادية وتعرف بأنها حالة الرضا العامة التي يعيشها الفرد نتيجة تقييمه

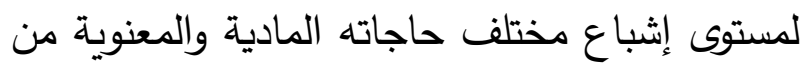

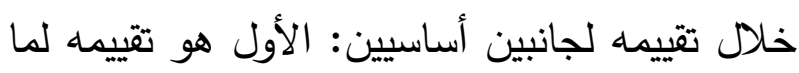

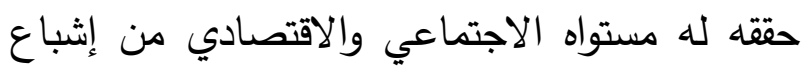
لحاجاته الأساسية. أما الجانب الثاني فهو تقييم مناخ التفاعل الاجتماعي داخل سياقات الحياة الاجتماعية (سلوى إبراهيم، ج . . ب).

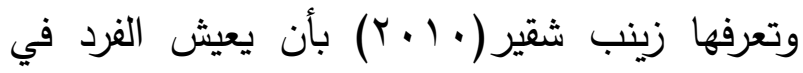
حالة جيدة متمتعا بصحة بدنية وعقلية وانفعالية على درجة من القبول والرضا، وأن يكون قوي الإرادة

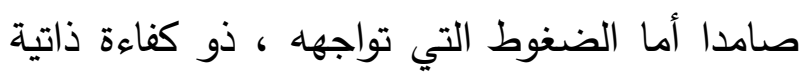
واجتماعية عالية، وراضيا عن حياته الأسرية والمهنية

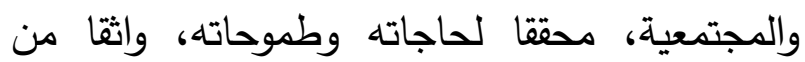
نفسه، غير مغرور ومقدرا لذاته بما يجعله متفائلا لحاضره ومستقبله، ومتمسكا بقيمه الدينية والخلقية والاجتماعية، ومنتميا لوطنه ومحبا للخير، ومدافعا عن حقوقه ومتطلعا للمستقبل. كما عرفت منظمة الصحة العالمية (WHO) جودة الحياة بأنها: قدرة الفرد على الاستمتاع بالإمكانيات

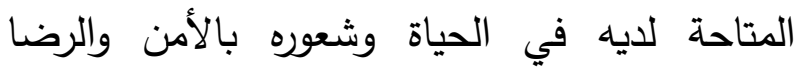
والسعادة والرفاهية، حتى ولو كان لديه ما يعوق ذلك لكان

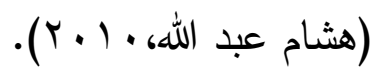

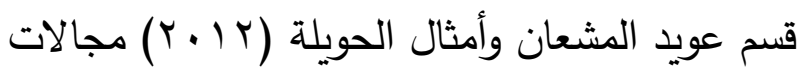

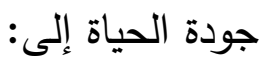


الدراسة وجود علاقة بين المساندة الاجتماعية والصحة العقلية؛ فقد تبين أن الحماية الاجتماعية للأسرة والدعم الاجتماعي للأصدقاء يرتبط بالصحة الصنة العقلية.

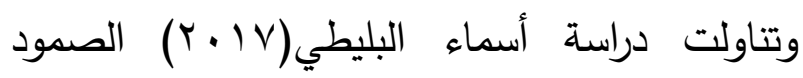
النفسي في علاقته بكل من المساندة الاجتماعية وجودة الحياة لدة عينة من الأطفال المعاقين حركيا، ومدى إمكانية التتبؤ بالصمود النفسي من خلال المساندة الاجتماعية وجودة الحياة، وشملت الدراسة (7) طفلا معاقا حركيا، واستخدمت مقاييس الصمود النفسي، والمسندة الاجتماعية، وجودة الحياة، وتوصلت النتائج إلى وجود علاقة دالة بين الصمود النفسي وكل من المساندة الاجتماعية وجودة الحياة، وكان مرتفعي المساندة الاجتماعية وجودة

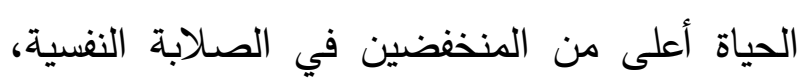
كما ظهر امكانية التتبؤ بالصمود النفسي من خلال المساندة الاجتماعية وجودة الحياة. واهتمت دراسة إسماعيل (1/ . r) بالتعرف على المساندة الاجتماعية لدى طلبة كلية الاعلام في جامعة بغداد والفروق باختلاف الجنس( ذكور -اناث ) والمرحلة الدراسية ( الأولى -المنتهية ) وتكونت عينة الدراسة من (0) 1 ) طالبا وطالبة، و أشارت النتائج

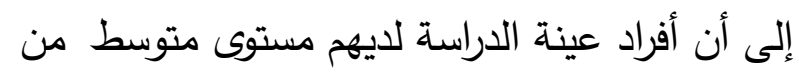
المساندة الاجتماعية، وكانت الإناث أعلى من الذكور في المساندة الإجتماعية، ولم توجد فروق تعزى إلى ملى المرحلة الدراسية.

\section{دراسات السابقة}

أولا:- دراسات تناولت المساندة الاجتماعية هدفت دراسة نسرين طنطاوي(T 1 • ( إ) إلى التعرف على القدرة التنبؤية للمساندة الاجتماعية بجودة الحياة

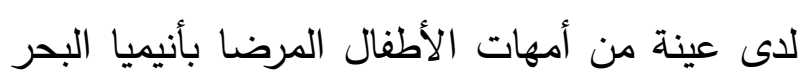
المتوسط (الثلاسيميا) وفقا لبعض المتغيرات الديموجرافية (سن الأم، المستوى التعليمي، عدد الأطفال التي ترعاهم الأم أسوياء- عدد الأطفال

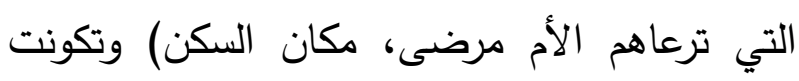

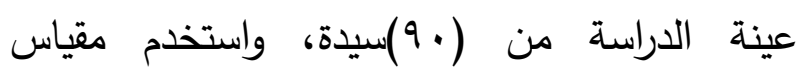
المساندة الاجتماعية ومقياس جودة الحياة، وتوصلت النتائج إلى وجود ارتباط دال بين المساندة الاجتماعية وجودة الحياة. كما هدفت دراسة عبد القادر(Y IV) إلى التعرف على العلاقة بين المساندة الاجتماعية وفعالية الذات، وكذلك التعرف على الفروق بين الذكور والإناث في

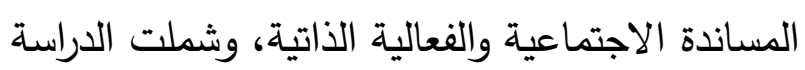

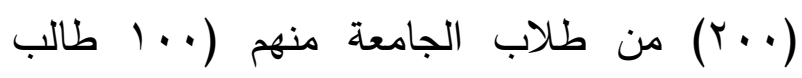

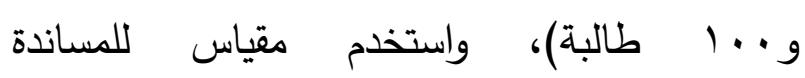
الاجتماعية، ومقياس لفعالية الذات. وأشارت نتائج الدراسة إلى وجود علاقة ارتباطية دالة بين المساندة

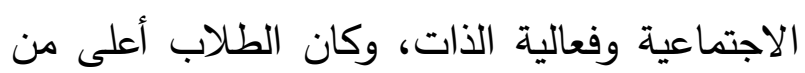
الطالبات في المساندة الاجتماعية وفعالية الذات. وتتاولت دراسة علي Ali) (2017 العلاقة بين المساندة الاجتماعية والصحة العقلية لطلاب جامعة

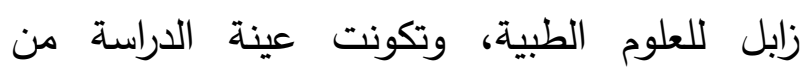
(. (0) طالب، وطبق استبيان الصحة العقلية، ومقياس المساندة الاجتماعية المدرك، وأظهرت نتائج 
وتوصلت النتائج وجود مستويات مرتفعة من فاعلية

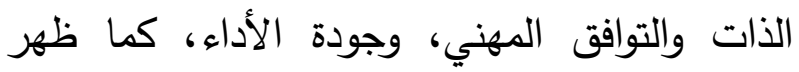
وجود علاقة ارتباطية بين فاعلية الذات والتوافق

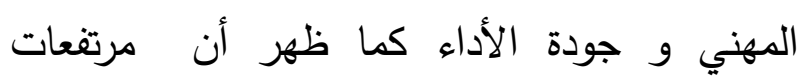
الفاعلية الذاتية أعلى من منخفضات الفاعلية الذاتية على مقياس التوافق المهني، ومقياس جودة الأداء. كما هدفت دراسة إريوزكان Erozkan, 2013 اختبار العلاقة بين مهارات التواصل ومهارات حل المشكلات الشخصية وفعالية الذات، وتعرف مدى لئى تتبؤ مهارات الاتصال ومهارات حل المشكلات بفعالية الذات الاجتماعية، تكونت عينة الدراسة من الاتصال ؟9 ـ من طلاب المدارس الثانوية بتركيا، منهم

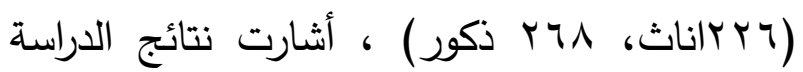
إلى أن مهارات التواصل ومهارات حل المشكلات

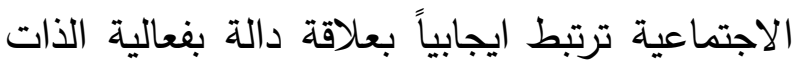
الاجتماعية، وتتنبأ أيضا بفعالية الذات الاجتماعية.

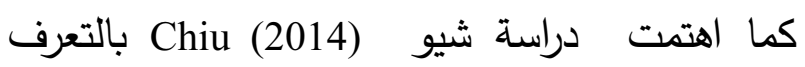

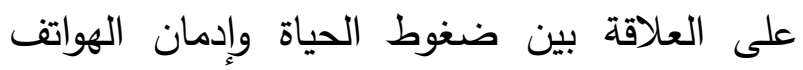
الذكية لدى طلاب الجامعة بتايوان، وتوصلت نتائج

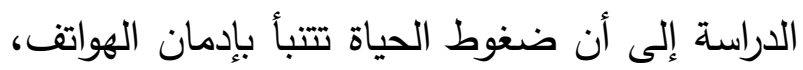
وتساهم فعالية الذات الاجتماعية كميكنزمات معرفية في توسط العلاقة بين الاحساس بالضغوط وإدمان

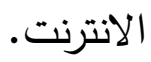
وهدفت دراسة عبدالله (10 ب ب) إلى معرفة العلاقة بين الضغوط الأكاديمية وكل من القلق وفعالية الذات

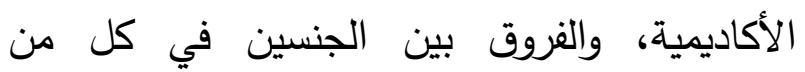
الضغوط الأكاديمية وفعالية الذات الأكاديمية، تكونت
Ming,Hui, في دراسة مينغ وآخرون (2018) Wang, Hai, Liang, Zhu آباء الأطفال الصينيين المصابين بالتوحد (الذين تتراوح أعمارهم بين س-1 الاطعال سنة) أشارت النتائج إلى لئين

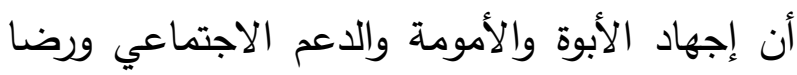

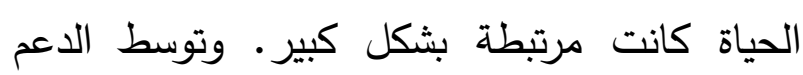

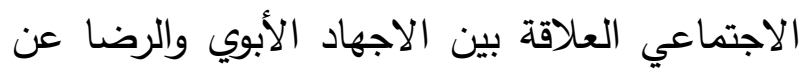

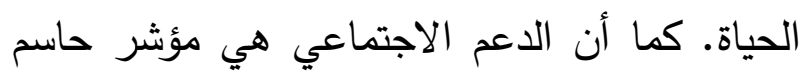
للرضا الحياة ويمكن أن تكون بمثابة استراتيجيات

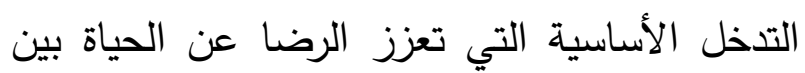
آباء وأمهات الأطفال الصينيين المصابين بالتوحد. ثانيا:- دراسات تناولت فعالية الذات Ahangi \& Sharaf ( تناولت دراسة آهانجي وشرف 2013 العلاقة بين فعالية الذات وموضع الضبط والتحصيل الدراسي لاى طلاب المرحلة الثانوية،

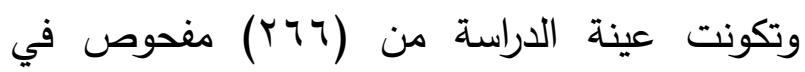
مدينة شينارن، واستخدام مقياس فعالية الذات، ومقياس وجهة الضبط. ومن أهم النتائج التي لتئن توصلت لها الدراسة أن لفعالية الذات دورا مهما في ومني الفي التتبؤ بالتحصيل الأكاديمي.

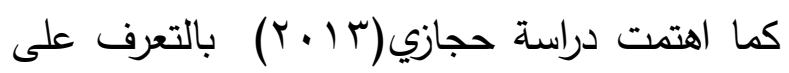

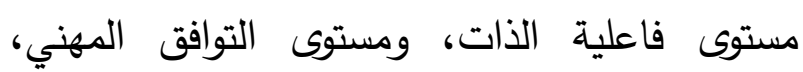

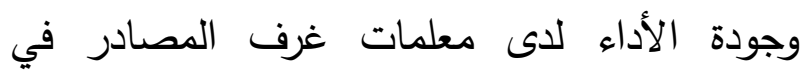
المدارس الحكومية في الضفة الغربية، وتكونت عينة الاراسة من (0؛) معلمة، واستخدم مقياس فاعلية

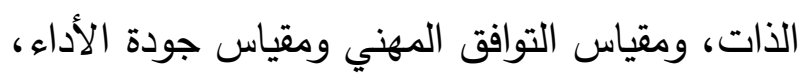


ثالثا:- دراسات تناولت جودة الحياة

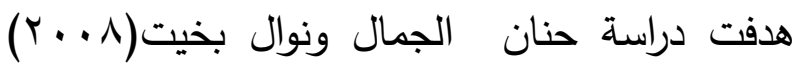
إلى التعرف على العلاقة بين قلق البطالة وكل من فعالية الذات وجودة الحياة لدى عينة من طلاب كلية التربية جامعة المنوفية (ن=ء 1 ( ) من طلاب الفرقة الرابعة، واطبق مقياس قلق البطالة ومقياس فعالية الذات ومقياس جودة الحياة، وتوصلت النتائج إلى وجود ارتباط سالب بين قلق البطالة وكل من فعالية الذات وجودة الحياة لاى عينة الدراسة. Moeini, Shafii, وتناولت دراسة موني وآخرون Hidarnia, Baboii, Birashk, Allahverdipour, (2008) جودة الحياة وعلاقتها بفاعلية الذات لدى

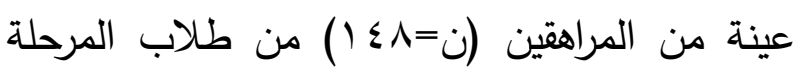
الثانوية بطهران، واستخدم مقياس لفاعلية الذات ومقياس لجودة الحياة، واسفرت النتائج عن دور فعالية الذات في التتبؤ بجودة الحياة، حيث تتعكس معتقدات فعالية الذات على إدراك النواتج والتوقعات

لديهح.

وقدمت دوستين Dustine(2009 دراسة هدفت إلى فحص المتغيرات التي تساهم في الشعور بجودة الحياة لى طلبة الجامعة(r (r) من طلاب الجامعة، وكشفت نتائجها عن وجود ارتباط موجب يين فعالية الذات العامة، وجودة الحياة ، كما ظهر أن جودة الحياة منبئ جيد لفعالية الذات العامة. وتتاولت دراسة زينب شقير ( • • ( العلاقة بين جودة الحياة واضطرابات النوم، ومدى انتشار جودة

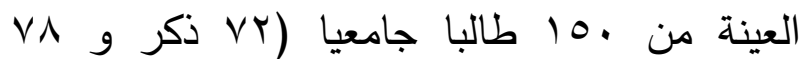
أنثى) بكلية الآداب جامعة القاهرة، وطبق مقياس الضغوط الأكاديمية ومقياس فعالية الذات الأكاديمية ومقياس القلق. وقد أسفرت النتائج عن وجود علاقة ارتباطية سالبة بين الضغوط الأكاديمية وفعالية الذات الأكاديمية، وكانت الإناث أعلى من الذكور في فعالية الذات الأكاديمية.

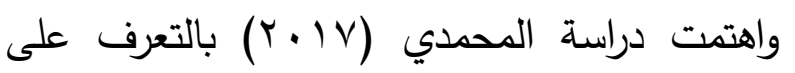
مدى تأثير وجهة الضبط (الداخلي والخارجي) وفعالية الذات على التحصيل الدراسي لطالبات المرحلة الثانوية، تكونت عينة الدراسة من (؟V) طالبة من طالبات المرحلة الثانوية.، واستخدم مقياس روتر ( Rotter ) لوجهة الضبط، ومقياس فاعلية الذات لشيرر وآدمز (Sherer \& Adams) ، وأظهرت النتائج أن مرتفعي فعالية الذات أعلى من منخفضي فعالية الذات في التحصيل الدراسي، وظهر وجود فروق في فعالية الذات تعزى للتخصص (علمي وأدبي). كما اتضح أنه يمكن التبؤ بالتحصيل الدراسي لطالبات المرحلة الثانوية من معرفة وجهة الضبط وفعالية الذات لديهن. (Adnan\& Berrin, وهدفت دراسة أوزيلماز وآخرون Aysegul, 2018) الذات في التنبؤ بمواقف وسلوكيات العمل ( الرضا لـالت الوظيفي)، وشملت الدراسة ( . . ب) موظف ومشرفيهم في مؤسسة صناعية في تركيا، وظهر أن الفعالية

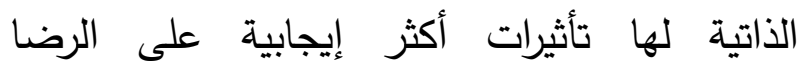
الوظيفي، وأداء المهام، وسلوكيات المواطنة. 
الحياة واضطرابات النوم لدى عينة من طلاب والمستوى الدراسي، وتكونت عينة الدراسة من

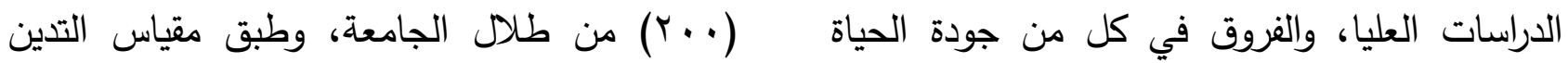

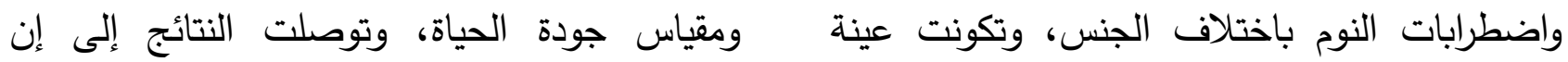
الدراسة من (090) من طلاب الدراسات العليا، مرتفعي التدين أعلى من منخفضي التدين في جودة فئه

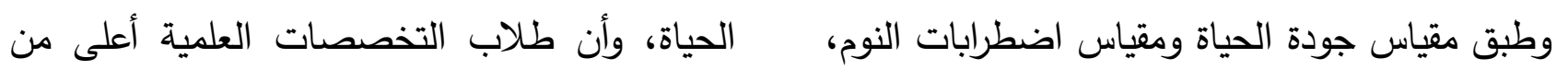
وبينت النتائج وجود ارتباط سالب بين جودة الحياة طلاب التخصصات الأدبية في كل من التدين وجودة

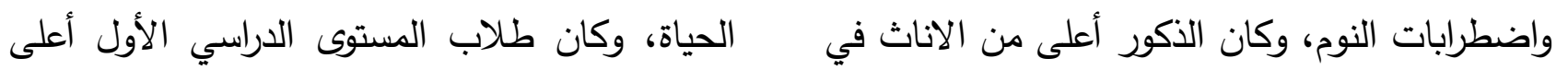

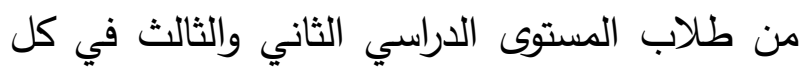

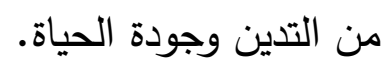

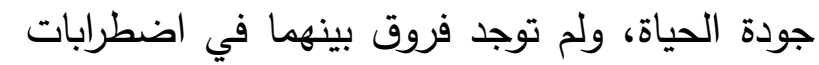

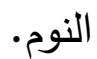

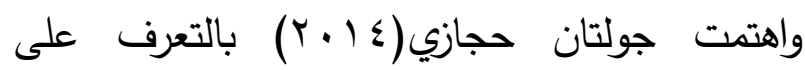
فاعلية برنامج ارشادي في تحسين جودة الحياة في

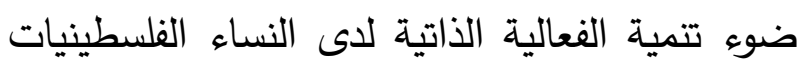
في مرحلة انقطاع الطمث، وتكونت عينة الدراسة من

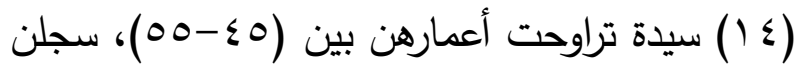
مستويات منخفضة من فعالية الذات وجودة الحياة، وأظهرت النتائج أن التطبيق لبعدي أعلى من التطبيق

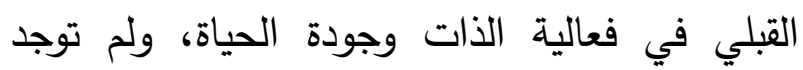

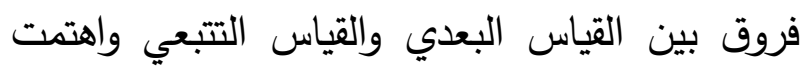

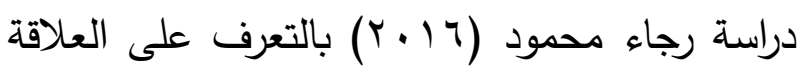
بين الصلابة النفسية وجودة الحياة من طالبات

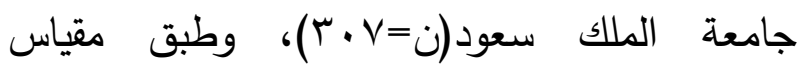
الصلابة النفسية ومقياس جودة الحياة، وتوصلت النتائج إلى وجود علاقة بين الصلابة النفسية وجود الحياة، وكانت طالبات تخصص علم النفس وإدارة الأعمال أعلى في الصلابة النفسية وجودة الحياة،

وتتاولت دراسة هويدا محمود وفوزية

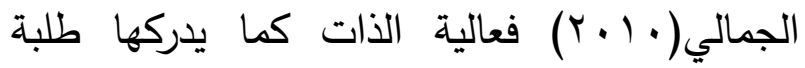
الجامعة من المتفوقين والمتعثرين وتأثيرها على جودة الحياة لديهم، واشتملت الدراسة (r.r) من طلاب الجامعة، واستخدم مقياس فعالية الذات ومقياس جودة الحياة، وتوصلت النتائج إلى وجود علاقة بين فعالية الذات وجودة الحياة، وكان الذكور أعلى من الإناث في جودة الحياة ولم توجد فروق بينهما في فعالية الذات ، وكان طلاب الاقسام العلمية أعلى من طلاب الاقسام الأدبية في فعالية الذات ، ولم توجد فروق بينهما في جودة الحياة، وكان الطلاب الطابه المتفوقين دراسيا أعلى من الطلاب المتأخرين دراسيا في كل من فعالية الذات وجودة الحياة. واهتمت دراسة عيد أبو عمرة وسوسن عبد الهادي

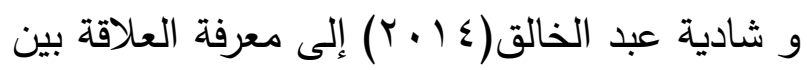
التدين وجودة الحياة لدى طلاب الجامعة، والفروق في كل من التدين وجودة الحياة وفقا للتخصص، وجدهاه 
- أن المساندة الإجتماعية تعزز الرضا عن الحياة، واتفقت بعض الدراسات انها مؤشر لجودة الحياة لدى الأفراد. - اتفقت بعض الدراسات على دور فعالية الذات في تحقيق جودة الحياة لدى الأفراد. - ندرة في الدراسات التي تتاولت جودة الحياه الحياة في علاقتها بالمسندة الاجتماعية وفعالية الذات بشكل

مجمع

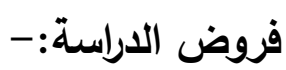

1- توجد علاقة دالة إحصائيا بين المساندة الاجتماعية وجودة الحياة لاى عينة من طالبات

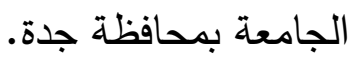
r- توجد علاقة دالة إحصائيا بين فعالية الذات وجودة الحياة لدى عينة من طالبات الجامعة

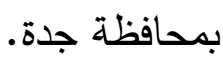
r- توجد فروق دالة إحصائيا في متوسطات درجات الطالبات في كلا من المساندة الإجتماعية وفعالية الذات وجودة الحياة تعزى إلى التخصص الأكاديمي. منهج الدراسة وإجراء اتها: أولا: منهج الداسة: استخدمت الباحثة المنهج الوصفي الارتباطي المقارن لدراسة علاقة متغيري فعالية الذات والمساندة الاجتماعية بجودة الحياة، حيث يوضح هذا المنهج

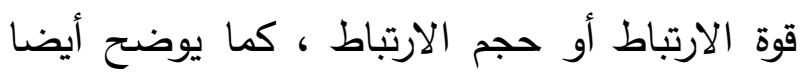

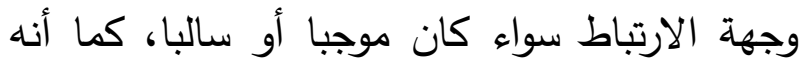
يمكن أن يعطينا تفسيرا للعلاقة بين المتغيرات يقترب الاتباه
كما أنه يمكن التتبؤ بجودة الحياة من خلال الصلابة

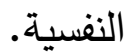

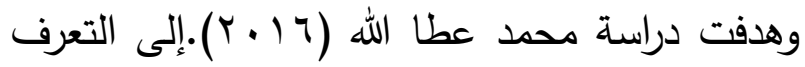
على العلاقة بين أساليب مواجهة الضغوط وعلاقتها بكل من فعالية الذات وجودة الحياة لاى عينة من

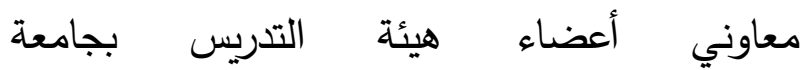
المنصورة(ن=.01)، واستخدم مقياس لأساليب مواجهة الضغوط، وفعالية الذات، وجودة الحياة، ومن أهم النتائج المرتبطة بالدراسة الحالية أن المرتفعين في جودة الحياة أعلى من المنخفضين في فعالية

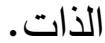

هدفت دراسة نعمة حسن(T 1 • Y) إلى تحديد القيمة التنبؤية لكل من فعالية الذات والدافعية للإنجاز بجودة الحياة لاى عينة من طالبات الدراسات العليا بكلية التربية جامعة الدمام، وتحديد الفروق بين التخصصات العلمية والتخصصات الأدبية في

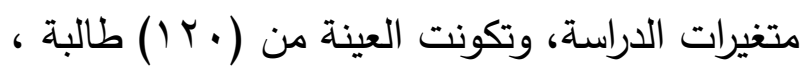
واستخدم مقياس فعالية الذات ومقياس الدافعية للإنجاز ومقياس جودة الحياة، وتوصلت النتائج إلى أنه يمكن التتبؤ بجودة الحياة من خلال فاعلية الذات والدافعية للنجاز، وعدم وجود فروق في متغيرات الدراسة تعزى إلى التخصص. التعليق على الدراسات السابقة من خلال العرض السابق للدراسات السابقة يتضح:- 


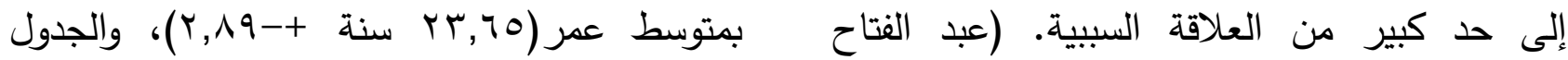
التالي يوضح خصائص العينة.

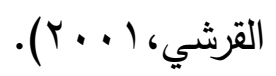

ثانيا: عينة الدراسة:

شملت الدراسة (• (Y) من طالبات الجامعة، ويتراوح

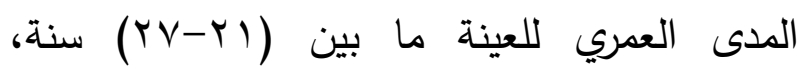
جدول رقم (1) يوضح خصائص العينة من حيث التخصص الأكاديمي

\begin{tabular}{|c|c|c|}
\hline النسبة المئوية & التكرار & الحالة \\
\hline$\% \varepsilon \cdot, q$ & 9. & علمية \\
\hline$\% 09,1$ & r. & نظرية \\
\hline$\% 1 \ldots$ & rr. & المجموع \\
\hline
\end{tabular}

من خلال الجدول نلاحظ أن 9, • ؛ ٪ من العينة تمثل تخصصات علمية ، مقارنة ب , 1\% من العينة تمثل تخصصات نظرية

\begin{tabular}{|c|c|c|}
\hline النسبة المئوية & التكرار & الفئة العمرية \\
\hline$\% 07, \wedge$ & iro & וץ-rזسنة \\
\hline$\% \leqslant r, r$ & 90 & צY- \\
\hline$\% 1 \ldots$ & rr. & المجموع \\
\hline
\end{tabular}

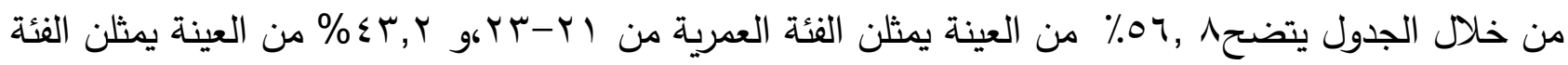

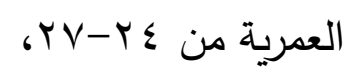

المساندة) ويم الاجابة على عبارات المقياس بالاختيار من (لا تنطبق، تنطبق بدرجة قليلة، تنطبق بدرجة متوسطة ، تتطبق بدرجة كبيرة) وتأخذ درجات

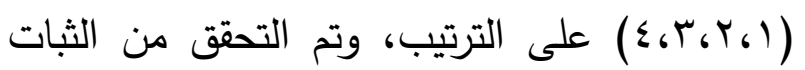

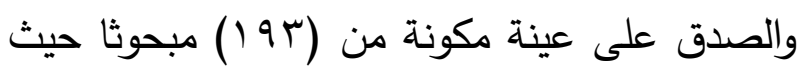
تم حساب الصدق من خلال الاتساق الداخلي
ثالثا : أدوات الدراسة: - مقياس المساندة الاجتماعية من إعداد فاطمة

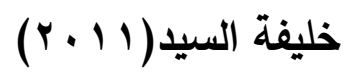
يتكون المقياس من (r/) عبارة تتضمن (؟) أبعاد

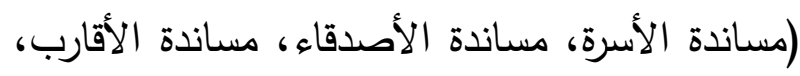

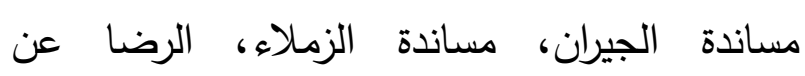


- مقياس جودة الحياة إعداد هشام عبد الله $(r \cdot 1 \cdot)$

العبارات من نوع التقرير الذاتي، حيث تتم الاستجابة على مفرداته في ضوء مقياس ثلاثي يتدرج من (تتطبق تماماً، تنطبق أحياناً، لاء تتطبق إطلاقاً)، ويتكون من سبعة أبعاد فرعية وهي الصحة الجسمية، الرضا عن الحياة، والتفاعل الاجتماعي، أنشطة الحياة اليومية، الحالة المادية، الصحة النفسية، السعادة وتصحح جميع مفرداته في الاتجاه الإيجابي

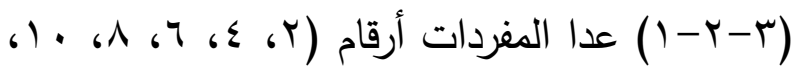

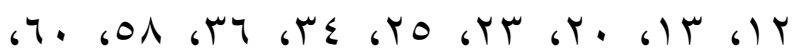
6 AV 6 17 6 10 6V9 6VE 679 67V 670 67

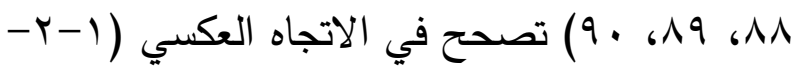
r)، وتم التحقق من صدق وثبات المقياس على

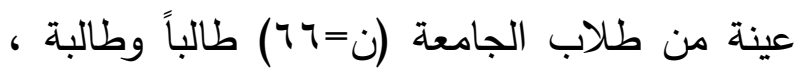
حيث تم التحقق من صدق المقياس من خلال صدق المحكمين، وصدق المقارنة الطرفية، والصدق التلازمي حيث تم استخدام مقياس جودة الحياة من إعداد: سامي هاشم (1 (Y) كمحك خارجي، وقد بلغ معامل الارتباط بين المقياسين على الدرجة الكلية (זT,,·)، كما تم حساب الثبات من خلال الاتساق الداخلي، ومعامل ألفا كرونباخ، وطريقة التجزئة النصفية، قيم معاملات الثبات انحصرت بين

$$
\cdot(\cdot, \wedge \wedge 6 \cdot, 0 \cdot)
$$

وتم اعادة حساب صدق وثبات المقاييس المستخدمة في الدراسة الحالية ، وذلك على عينة من طالبات الجامعة (ن= • ب)، تراوحت أعمارهم بين (Y (Y-
بحساب معامل الارتباط بين درجة البند والأبعاد الفرعية، وتراوحت معاملات الارتباط بين (9 ب, ، (, >9 معامل الارتباط بين المقياس الحالي ومقياس المساندة الاجتماعية إعداد شعبان جاب الله رضوان، وبلغ معامل الارتباط (99,))، كما تم حساب ثبات المقياس بطريقة ألفا كرونباخ ووصل إلى (VT, ) ، وبطريقة التجزئة النصفية (ه9,)، وإعادة التطبيق بفاصل زمني (· () أيام (ن=.ب)، وبلغ (YY,)؛

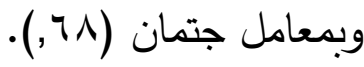
- مقياس فعالية الذات إعداد نهاد محمود (7 1 ( ب) يتكون المقياس في صورته النهائية من (·) بند لقياس فعالية الذات العامة والتي تشتمل على ثلاثة أبعاد رئيسية هي: المبادأة، والمجهود، والمثابرة. ويجاب على بنود المقياس من خلال عدة درجات تتكون من خمس مستويات

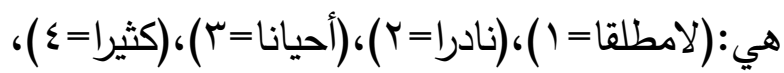
(كثيرا جدا=0). وذلك باستثناء البنود أرقام (1-rم-1-1 عكسي. وتم حساب ثبات ألفا كرونباخ للمقياس ككل وبلغ هذا المعامل(r,,•) ويشير ذلك إلى قياس جميع مفردات المقياس لنفس المضمون. وتراوح معاملات ارتباط درجة البند بالدرجة الكلية للمقياس ما بين( اس, · و rT, • ) وهي معاملات متوسطة إلى مرتفعة دالة عند مستوى ا + . , . . 


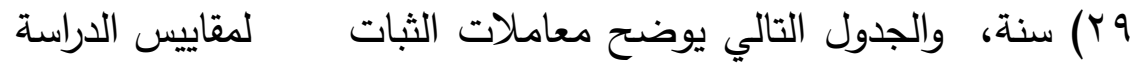
جدول رقم (ץ) يوضح معاملات ثبات مقاييس الدراسة

\begin{tabular}{|c|c|}
\hline معامل الفا كرونباخ & معاهل الثبات \\
\hline & الدقاييس \\
\hline, 71 & المساندة الإجتماعية \\
\hline, $0 \mathrm{~V}$ & فعالية الذات \\
\hline זד, & جودة الحياة \\
\hline
\end{tabular}

نتائج الدراسة ومناقشتها الفرض الأول:- وينص على توجد علاقة دالة إحصائيا بين المساندة الاجتماعية وجودة الحياة لدى عينة من طالبات

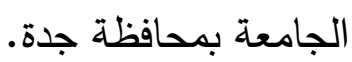

وللتحقق من صحة الفرض تم حساب بهد معامل الارتباط بيرسون بين درجات الطالبات على مقياس المساندة الاجتماعية ومقياس جودة الحياة.

يتضح من الجدول السابق تمتع مقاييس الدراسة بدرجة عالية من الثبات، ويعد ذلك مؤشرا جيدا لهابل لاستخدام هذه المقاييس في الدراسة الحالية. كما تم حساب الاتساق الداخلي بحساب معامل الارتباط بين درجة كل عبارة والدرجة الكلية للمقاييس الثلاثة وتراوحت معاملات الارتباط لمقياس المساندة

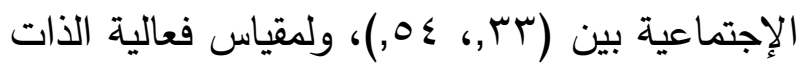

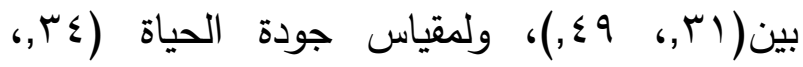
.$(, 07$

جدول رقم (ع) يوضح معاملات الارتباط بين كلا من المساندة الإجتماعية وجودة الحياة لاى عينة الدراسة

\begin{tabular}{|c|c|c|c|c|c|c|c|c|c|}
\hline لالدقياس الكلية & \multicolumn{7}{|c|}{ أبعاد جودة الحياة } & & \\
\hline & السعادة & النفسية & العادية & ألنثطة & الاجتماعي التفاعل & الرياة الرضا & الصحمية & & \\
\hline$" *, 0 \leqslant$ & $\because, 0$, & $\because, r q$ & $\because, r q$ & $\because, r v$ & $\because, \leq \leqslant$ & $*, r \varepsilon$ & " $, r, r$ & مساندة الأسرة & \multirow{6}{*}{ 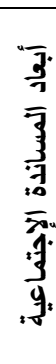 } \\
\hline$" *, \leqslant 7$ & "*,$\leq \leqslant 7$ & "*.,$\leqslant 0$ & 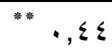 & $" \cdot, \leqslant \wedge$ & " . rV & $\cdots \cdot, r q$ & $" *, \leqslant 0$ & مساندة الأصدقاء & \\
\hline " " " & " , Y & $", r V$ & $\because, Y \Lambda$ & "* 07 & $*, 0$. & $* *, \leqslant 9$ & $" *, \leqslant V$ & مساندة الأقارب & \\
\hline " & $", r \leq$ & $*, Y \wedge$ & $\because, r \leq$ & זr, "ט & 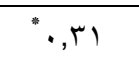 & " & $\because, r r$ & مساندة الجيران & \\
\hline$" ., \mu \varepsilon$ & $" \cdot, r V$ & $\because, 49$ & "., ro & $", r$. & " & " & "., & مساندة الزملاء & \\
\hline$\because$, , & $" *, \leqslant Y$ & ${ }^{* *} \cdot, \leqslant 9$ & 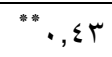 & $" ., 00$ & $"$ ".,or & $" *, \varepsilon 7$ & $" *, r q$ & الرضا عن المساندة & \\
\hline$" *, \cdot \leqslant \wedge$ & $" \because$, , & $\because, r_{q}$ & $* * *, \leqslant \wedge$ & $" ., 00$ & $" *, 0$. & $" *, \varepsilon \leq$ & $\because, r V$ & ماندة الإجتماعية لكقية & \\
\hline
\end{tabular}

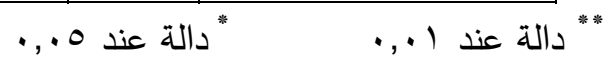


للحياة تساعد لمواجهة أضرارها، وتقلل من الضغوط المحتملة التي تصيب الأفراد على كافة الأعمار.

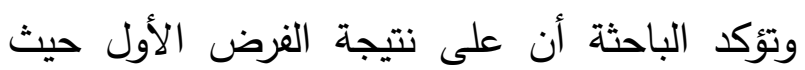
كلما توافر لاى الفرد شبكة علاقات إجتماعية متمثلة

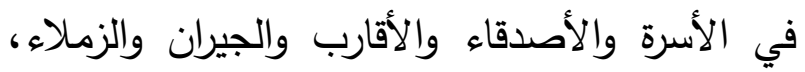
وحصل منها على الدعم الاجتماعي يعد ذلك مؤشر والأشر واهر

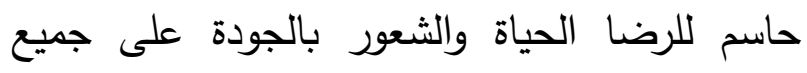
النواحي (الصحية، والنفسية، والإجتماعية) كما يمكن

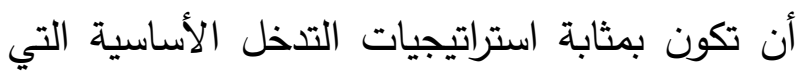
تعزز الرضا عن الحياة لديهم لفئابة اليتريات الفرض الثاني: وينص على الثى توجد علاقة دالة إحصائيا بين فعالية الذات وجودة الحياة لاى عينة من طالبات الجامعة بمحافظة جدة.

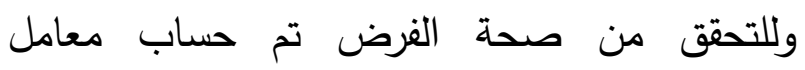
الارتباط بيرسون بين درجات الطالبات على مقياس فعالية الذات ومقياس جودة الحياة.
يتضح من الجدول السابق وجود ارتباط دال بين المساندة الإجتماعية وأبعادها الفرعية (مساندة الأسرة، مساندة الأصدقاء، مساندة الأقارب، مساندة

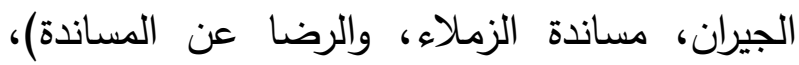

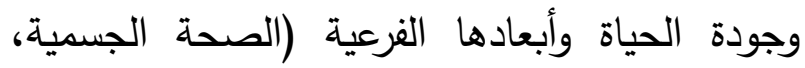

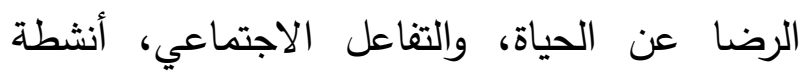

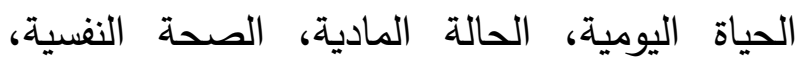

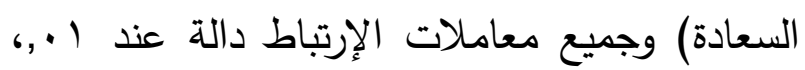

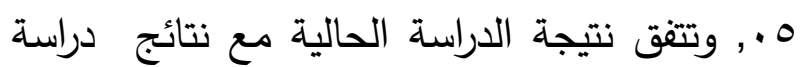

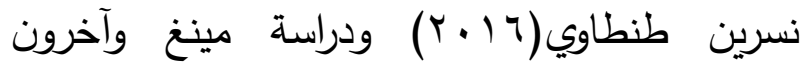
كما تتفق نتيجة الدراسة الحالية مع الأطر النظرية التي توضح أن الشعور بجودة الحياة يزداد أو يقل وفق المنظومة المحيطة

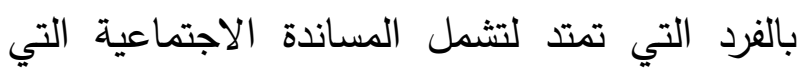
تقدم للأفراد لمواجهة ضغوط الحياة ، كما أنها تزبد لتئل

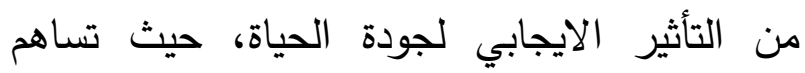
المساندة الاجتماعية المادية والمعنوية برؤية تنبؤية الايجية جدول رقم (•) يوضح معاملات الارتباط بين فعالية الذات وجودة الحياة لاى عينة الدراسة

\begin{tabular}{|c|c|c|c|c|c|c|c|c|c|}
\hline لكقياس جودة الكلية & \multicolumn{7}{|c|}{ أبعاد جودة الحياة } & & \\
\hline & السعادة & النفسية & الحادية & النياة & الاجتماعي & الرين & الجسمية & & \\
\hline "*., & $" \cdot \cdot, \varepsilon r$ & $\cdot, r$, & $\because, r_{0}$ & ${ }^{*} \cdot, \varepsilon r$ & $\because \cdot, \sum \lambda$ & $" \cdot, r q$ & $\because, \varepsilon_{0}$ & العبادأة & \multirow{3}{*}{ 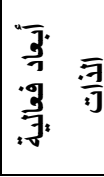 } \\
\hline$\because, 07$ & יז, & "• & "• & $\ddots, r q$ & ${ }^{*} \cdot, \varepsilon V$ & $\begin{array}{l}*, 01 \\
\end{array}$ & $\because, r q$ & المجهود & \\
\hline${ }^{*} \cdot, \varepsilon r$ & $\because, Y \Lambda$ & $\because, r q$ & $\cdot \cdot$, rᄉ & ${ }^{*} \cdot, 0 r$ & $\because, 01$ & ${ }^{\prime} \cdot, 00$ & 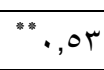 & المثابرة & \\
\hline${ }^{*} \cdot$, , & $\because \cdot, \leqslant 9$ & $\because \cdot, r q$ & " • & $\because ., 09$ & ${ }^{\prime} \cdot, 01$ & & " & \multicolumn{2}{|c|}{ الارجة الكلية ليقياس فعالية } \\
\hline
\end{tabular}


يتضح من الجدول السابق وجود ارتباط دال بين الهامة التي توجه سلوك الفرد وتسهم في تحقيق

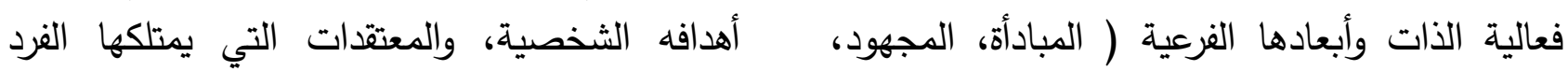

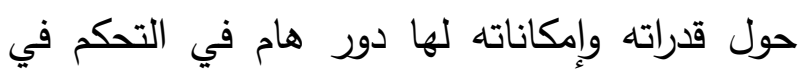

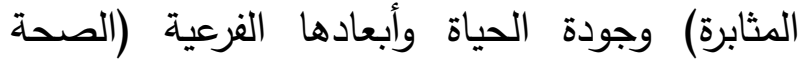
البيئة؛ مما يسهم في زيادة قدرة الفرد على الإنجاز

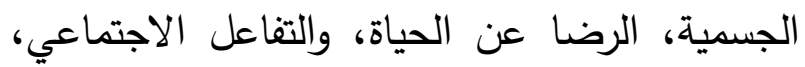

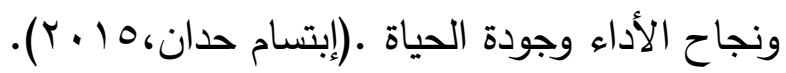

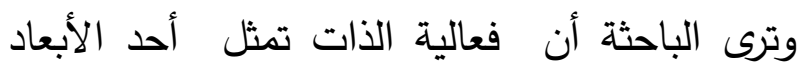

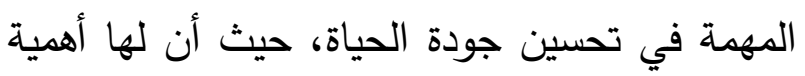
بالغة في حياتتا، وترجع أهميتها إلى الدور الحيوي

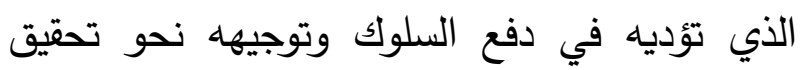

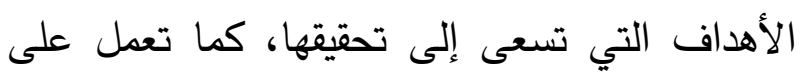
تحسين أداء العمل فيضع الطالب لنفسه أهدافا بعيدة تصنية

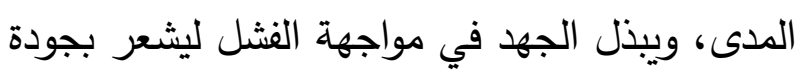

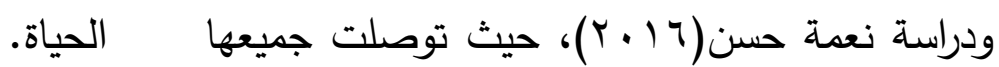
الفرض الثالث: وينص على

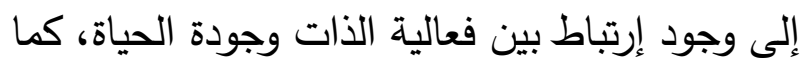
توجد فروق دالة إحصائيا في متوسطات درجات درات المات الطالبات في كلا من المساندة الإجتماعية وفعالية الذات وجودة الحياة تعزى إلى التخصص الطيات الأكاديمي.

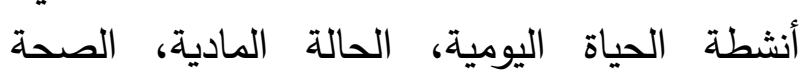

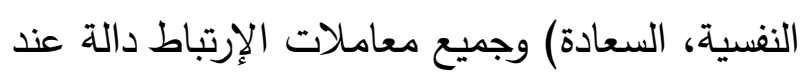

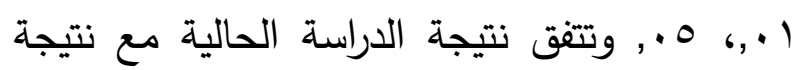

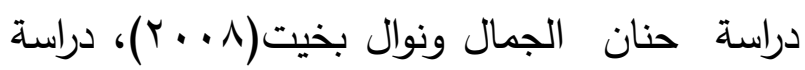

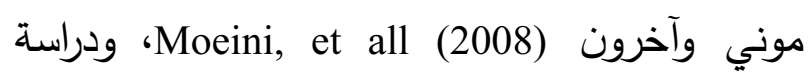
دوستين Dustine(2009) ، ودراسة زينب شقير

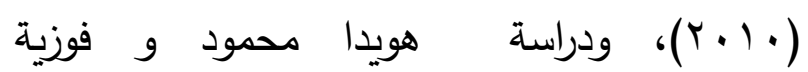

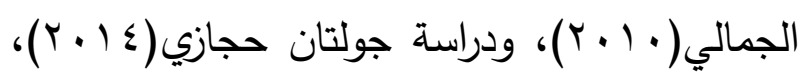
أنه يمكن التنبؤ بجودة الحياة من خلال فعالية الذات فئل الدات

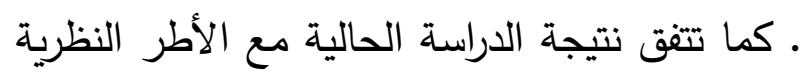

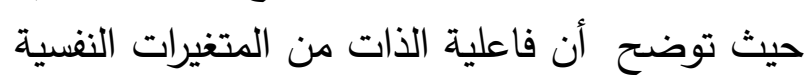
جدول رقم (†) يوضح اختبار (ت) للكثف عن الفروق في كلا من المساندة الإجتماعية وفعالية الذات وجودة الحياة الحياة

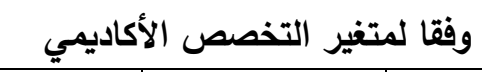

\begin{tabular}{|c|c|c|c|c|c|}
\hline مستوى الدلالة & قيمة (ت) & المعياري & المتوسط الحسابي & التخصص الأكاديمي & المتغير \\
\hline \multirow{3}{*}{ غير دالة } & \multirow{2}{*}{$1, r \varepsilon$} & $r, r_{0}$ & $\mid \nvdash \Lambda, \varepsilon$ & علمية & المساندة \\
\hline & & $r \cdot, r_{\Lambda}$ & $I T Y, A$ & نظرية & الاجتماعية \\
\hline & & الالنحراف & المتوسط الحسابي & التخصص الأكاديمي & \\
\hline \multirow{3}{*}{ غير دالة } & \multirow{2}{*}{$1,1 \varepsilon$} & $r+, \varepsilon 0$ & 119,0 & علمية لعية & \multirow{2}{*}{ فعالية الذات } \\
\hline & & ro,rr & $\| \mathrm{V}, \mathrm{A}$ & نظرية & \\
\hline & & المعياري & المتوسط الحسابي & التخصص الأكاديمي & \\
\hline \multirow{2}{*}{ غير دالة } & \multirow{2}{*}{$1, \wedge 9$} & $r, T)$ & $\mid T r, \varepsilon$ & علمية & \multirow{2}{*}{ جودة الحياة } \\
\hline & & $r, r$. & $1 \% 0,1$ & نظرية كن كن & \\
\hline
\end{tabular}


الأكاديمي إلى تشابهه الظروف البيئية والاقتصادية والإجتماعية التي يعيشها طلاب الجامعة في جميع

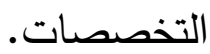
توصيات الدراسة:- الاستفادة من الخدمات الطلابية في رفع الكفاءة الذاتية للطلاب وادرالك جودة الحياة لديهج • - التوسع في اجراء الدراسات التي تبحث في الشخصية الانسانية والتعرف على جوانب القوة فيها

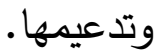

- ضرورة توعية الوالدين برورة المساندة الاجتماعية لأبنائهر وخاصة في المرحلة الجامعية حتى تنضج شخصيتهم.

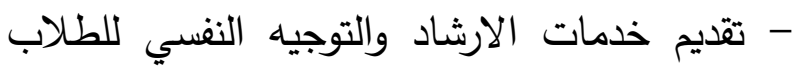
لمرحلة الجامعية، وحثهم على تحسين علاقتهم

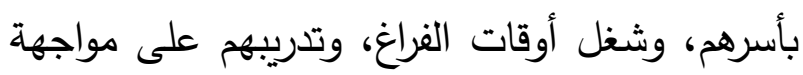
المشكلات للاستمتاع بحياتهم. - تذليل كافة الصعوبات التي تواجهه الطلاب سواء

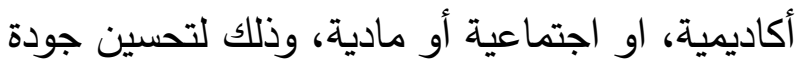

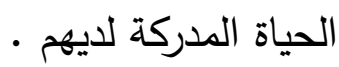
تهيئة مناخ تربوي بالجامعات يشجع على تتمية فعالية الذات ورفع روح التوافق في المرحلة الجامعية. مقترحات الدراسة :-

- اجراء المزيد من الدراسات التي تربط بين جودة الحياة والمتغيرات الايجابية كالتفاؤل والصلابة لتربة لهنية النفسية، والصمود النفسي.
يتضح من الجدول السابق عدم وجود فروق دالة بين طالبات التخصصات العملية، وطالبات التخصصات النظرية في جميع متغيرات الدراسة(المساندة الإجتماعية، وفعالية الذات، وجودة الحياة) ، ومن خلال مراجعة الدراسات السابقة يتضح وجود ندرة في الدراسات التي اهتمت بالفروق بين ذوي التخصصات العلمية والتخصصات النظرية في المساندة الإجتماعية ، بينما ما يخص فعالية الذات

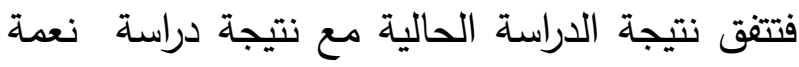
حسن (T 1 (Y)، حيث أظهرت عدم وجود فروق في فعالية الذات نعزى إلى التخصص الأكاديمي، في حين أوضحت دراسة هويدا محمود و فوزية الى التية

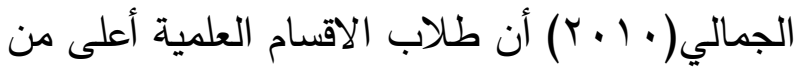
طلاب الاقسام الأدبية في فعالية الذات . أما بالنسبة لمتغير جودة الحياة فتتفق نتيجة الدراسة الحالية مع نتيجة دراسة هويدا محمود و فوزية

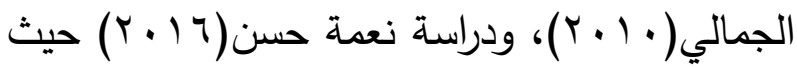
لم توجد فروق في جودة الحياة تعزى للتخصص الأكاديمي، في حين اختلفت نتيجة الدراسة الحالية مع نتيجة دراسة عيد أبو عمرة وسوسن عبد عادئ

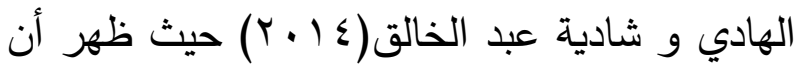
طلاب التخصصات العلمية أعلى من طلاب التخصصات النظرية في جودة الحياة، وترجع الباحثة نتيجة الفرض الحالي فيما يخص عدم وجود

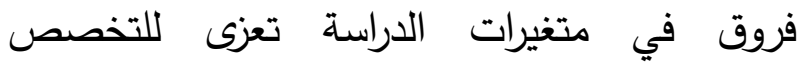


الحياة الأكاديمية لدى طلاب الجامعة. مجلة كلية التربية

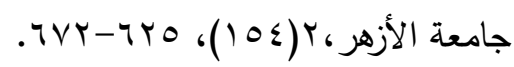

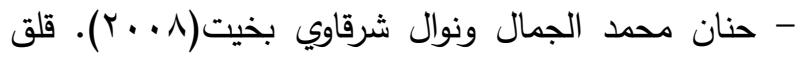
البطالة وعلاقته بجودة الحياة وفاعلية الذات لدى طلاب السنة النهائية بكلية التربية جامعة المنوفية. مجلة البحوث النفسية

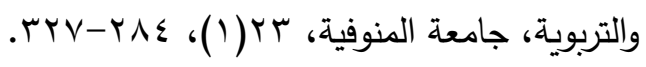

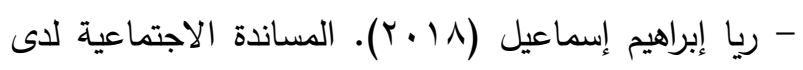
طلبة كلية الاعلام في جامعة بغداد. مجلة الأكاديمية

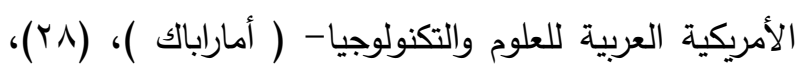
. $) \leqslant r-1 Y q$ - زينب محمود شقير( • ( • (Y). جودة الحياة واضطرابات

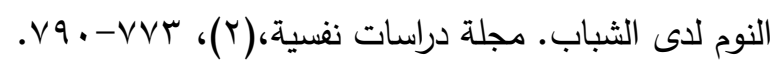

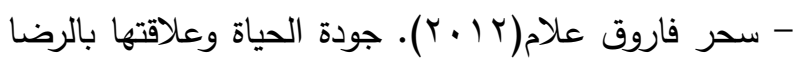
الوظيفي لاى عينة من أعضاء هيئة التدريس بالجامعة. مجلة

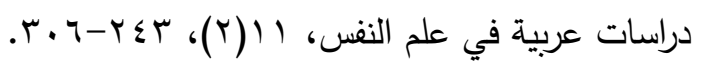

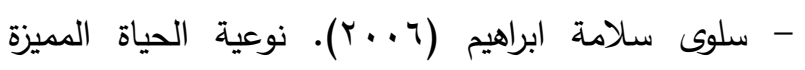
للمبدعين في الأدب. مجلة دراسات عربية في علم النفس، Or.r.r.

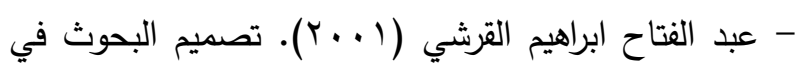
العلوم السلوكيية، الكويت: دار القلم.

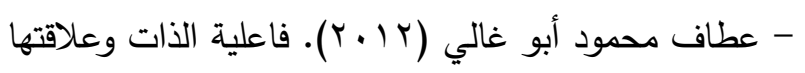
بضغوط الحياة للى الطالبات المتزوجات في جامعة الأقصى. مجلة الجامعة الإسلامية للدراسات التربوية

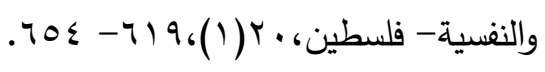

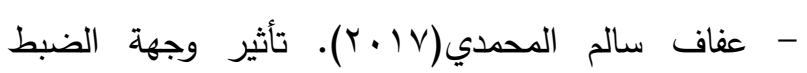
(الداخلي والخارجي) وفعالية الذات على التحصيل الدراسي

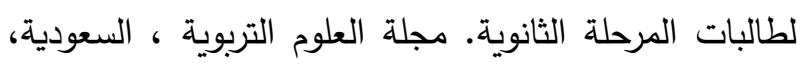

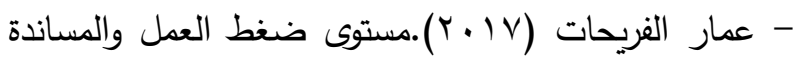
الاجتماعية لدى معلمي المرحلة الثانوية في محافظة عجلون
- تصميم برامج إرشادية لتنمية فعالية الذات وجودة

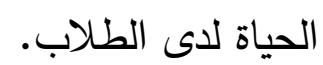

\section{قائمة المراجع}

أولا: المراجع العربية - إبتسام حدان (10 (ب). فاعلية الذات وعلاقتها بالألم المزمن :دراسة مقارنة لدى عينة من المرضى وغير المرضى بمدينة ورقلة. رسالة ماجستير، كلية العلوم الإنسانية والاجتماعية، جامعة قاصدي مرباح ورقلة.

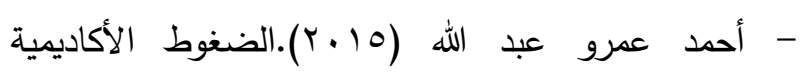
وعلاقتها بكل من القلق وفعالية الذات الأكاديمية بين طلبة

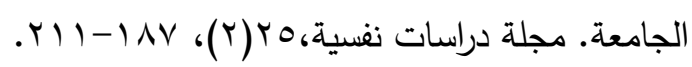

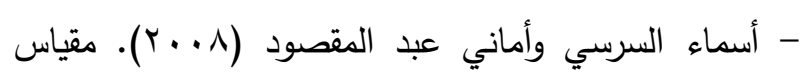
المساندة الاجتماعية. القاهرة: مكتبة الانجلو المصرية.

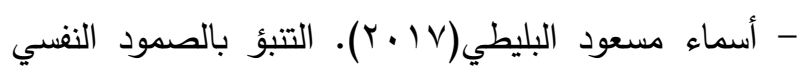

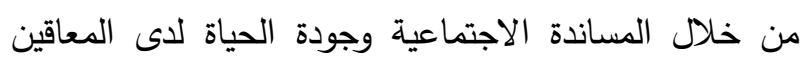

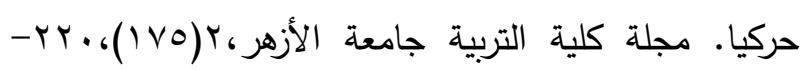
. T.

- جاء محمود مريم(7 1 ب). الصلابة النفسية وعلاقتها بجودة الحياة لدى طالبات جامعة الملك سعود. مجلة دراسات

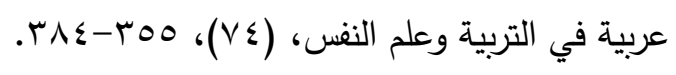

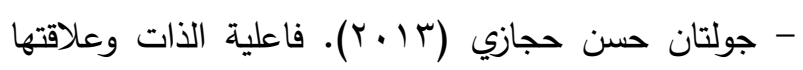

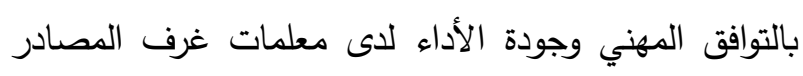
في المدارس الحكومية في الضفة الغربية. المجلة الأردنية في

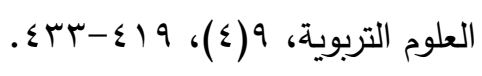

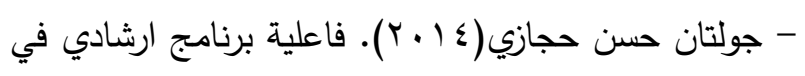

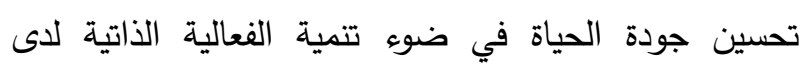
النساء الفلسطينيات في مرحلة انقطاع الطمث. مجلة البحث

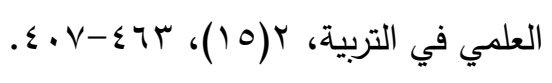

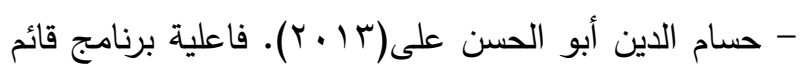
على مهارات التفكير في تتمية أساليب التفكير وتحين جودة 
الإسلامية بغزة. رسالة ماجستير، كلية التربية، الجامعة الإسلامية(غزة).

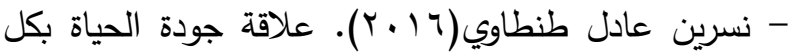
من المساندة الاجتماعية والمتغيرات الديموجرافية لأمهات الأطفال المصابين بأنيميا البحر المتوسط (الثلاسيميا). مجلة

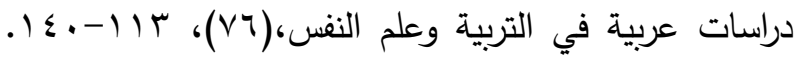

- نعمة عبد السلام حسن(T (Y). القيمة التنبؤية لفعالية الذات والدافعية للإنجاز بجودة الحياة لاى طالبات مرحلة الدراسات العليا بكلية التربية. مجلة كلية التربية في العلوم

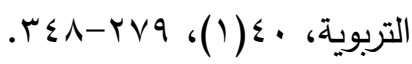

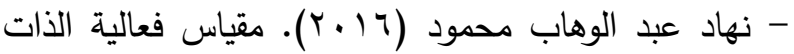
العامة. القاهرة: مكتبة الأنجلو المصرية. - هدى ميلاد عبدالقادر و بدرية كمال أحمد(Y) (Y). المساندة الاجتماعية وعلاقتها بفعالية الذات لدى عينة من فن

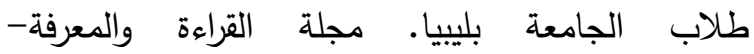
مصر، (1) - هثام (براهيم عبد الله(· • • (Y). مقياس جودة الحياة للراشدين. جده: مكتبة الشقري. - هويدا حنفي محمود و فوزية عبد الباقي الجمالي( • ( • ب).

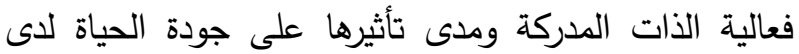
طلبة الجامعة من المتفوقين والمتعثرين دراسيا. مجلة

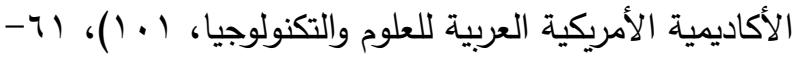

\section{المراجع الأجنبية}

- Adnan, O., Berrin, E., Aysegul, K .( 2018) .Trust in organization as a moderator of the relationship between self-efficacy and workplace outcomes: A social cognitive theory-based examination. Journal of

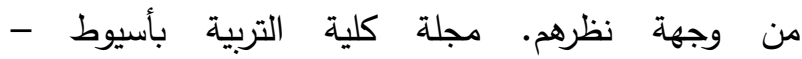

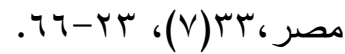
- عويد سلطان المشعان وأمثال هادي الحويلة(Y ( ب). الفرق بين نوعية الحياة لاى طلبة جامعة الكويت وفق الجنس والحالة الصحية. المجلة التربوية، (ع • ()، 0 (1)

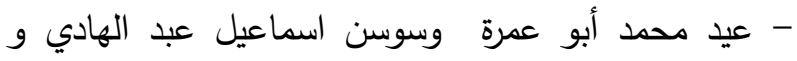

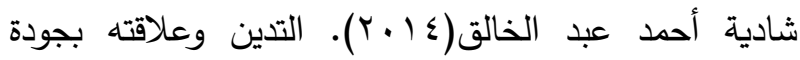
الحياة لدى طلاب الجامعة. مجلة البحث العلمي في التربية ، $.41 .-119$ ، (10)r - فاطمة خليفة السيد(1) (1) ب). دور بعض المتغيرات النفسية في التتبؤ بالرضا عن الحياة لدى عينة من مرضى الفشل الكلوي. رسالة دكتوراة، قسم علم النفس، كلية الآداب، جامعة هردئ

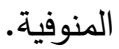

- فضل إبراهيم عبد الصدد (T . . ץ).الشعور بالأمل والرغبة في التحكم لدى عينة من طلاب الدراسات العليا بجامعة المينا

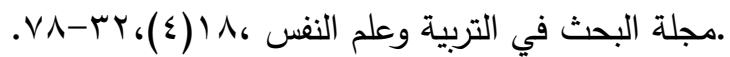
- ليلى عبد الله المزروع(V . . r).فاعلية الذات وعلاقتها بكل من الدافعية للإنجاز والذكاء الوجداني لدى عينة من طالبات جامعة أم القرى. مجلة العلوم النفسية والتربوية- البحرين ، $. \wedge 9-7 \vee \cdot(\varepsilon)^{\wedge}$ - محمد ابراهيم عطا الله(T 1 • ب). أساليب مواجهة الضغوط النفسية وعلاقتها بفاعلية الذات وجودة الحياة لدى معاوني أعضاء هيئة التدريس بجامعة المنصورة. مجلة الارشاد

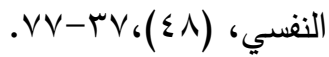

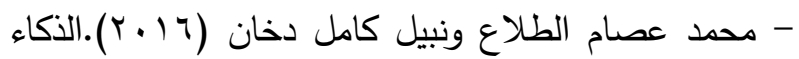
الروحي وعلاقتة بالصمود النفسي للى طلبة الجامعة Occupational and Organizational Psychology,88(1), 181-204.

- Ahangi, A \& Sharaf, Z .(2013). Investigating the relationship between self -efficacy the locus of control and male and female student's academic achievements in Chenaran high 
school. Journal of Engineering Research and Applications, 3(5), 875- 879.

- Backstrom, C., Larsson, T., Wahlgren, E., Golsater, M. ,Martensson, L., Thorstensson, S.(2010 ) .It makes you feel like you are not alone Expectant first time mothers-experiences of social support within the social network when preparing for childbirth and parenting.Sex Reprod Healthc, 12, 51-57.

- Bandura, A. (2007). Much ado over a faulty conception of perceived self- efficacy grounded in faulty experimentation. Journal of Social and Clinical Psychology, 26 (6), 641658.

- Chiu, S (2014) The relationship between life stress and smartphone addiction on taiwanese university student: A mediation model of learning self-Efficacy and social self-Efficacy, Computers in Human Behavior,9(34), 49-57.

- Del-Pino-Casado, R., Froas-Osuna, A,. Palomino-Moral, P., Ruzafa-MartõÂnez, M., Ramos-Morcillo, A .(2018). Social support and subjective burden in caregivers of adults and older adults; metaanalysis.13(1), 1-18.

- Dustine, R. (2009). The relationship of Gratitude and subjective well-being to selfefficacy and control of learning beliefs among college students. Faculty of the Rossier school of Education University of Southern California. Unpublished Doctoral Dissertation. - Erozkan, A (2014) Analysis of Social Problem Solving and Social Selfefficacy in Prospective Teachers. Educational Sciences: Theory \& Practice, 14 (2),447-45.

- Lu, M., Guang-Hai ,W., Lei, H., Shi, M., Rui ,Z., al, E .( 2018). Social Support as Mediator and Moderator of the Relationship Between Parenting Stress and Life Satisfaction Among the Chinese Parents of Children with ASD . Journal of Autism and Developmental Disorders; New York ,48(4), 1181-1188.

- Mermer, G., Bilge, A., Yucel, U., Ceber, E. (2010). Evaluation of perceived social support levels in pregnancy and postpartum periods. $\mathrm{J}$ Psychiatr Nurs, 1(2), 71-76.

- Moeini, B.; Shafii, F.; Hidarnia, A.; Baboii, G.; Birashk, B. \& Allahverdipour, H. (2008). Perceived stress, self-efficacy and its relations to psychological wellbeing status in Iranian male high school students. Social Behavior and Personality, 36 (2), 257-266.

- Nasiri, A. (2017). An Assessment of the Relationship between Social Support and Mental Health of Students of Zabol University of Medical Science. Middle East Journal of Family Medicine, 15(10), 242-253. 


\title{
Social Support, Self-efficacy and it's relation with Quality of life among a Sample of female university students in Jeddah
}

\author{
Shrooq Gharmallah Alzahrani \\ Assistant professor of Psychology \\ Faculty of Social Sciences - Jeddah university
}

\begin{abstract}
Social Support and Quality of life, also the relation between Self-efficacy and Quality of life, as well as the differences in study variables led to Academic Specialization, This study includes a sample of university student $(\mathrm{N}=210)$, the researcher used Social Support scale , Self-efficacy scale, and Quality of life scale. The result showed that a relation between Social Support and Quality of life, also a relation between Self-efficacy and Quality of life, there was differences in study variables led to academic Specialization,
\end{abstract}

Key words:- Social Support- Self-efficacy - Quality of life- female university students 